\title{
Endotracheal Tube Extubation Force: Adhesive Tape Versus Endotracheal Tube Holder
}

\author{
Takeru Shimizu MD PhD, Taro Mizutani MD PhD, Soichiro Yamashita MD PhD, \\ Keiichi Hagiya MD, and Makoto Tanaka MD PhD
}

\begin{abstract}
BACKGROUND: Adhesive tape is commonly used to secure the endotracheal tube (ETT) in anesthesia and intensive-care settings. OBJECTIVE: To determine the force required to extubate when the ETT is secured with adhesive tape or commercially available ETT holders. METHODS: We orally intubated a simulation manikin with a standard 8.0-mm inner-diameter ETT, inflated the cuff to $20 \mathrm{~cm} \mathrm{H}_{2} \mathrm{O}$, and measured the force required to extubate with the ETT secured in several ways. We tested 3 brands of tape (Durapore, Multipore Dry, and Wardel) with 6 methods, and 2 commercially available ETT holders (LockTite and Thomas) with one method. We also tested a bite block (Universal Bite Block) with 2 methods. We used a releasable cable tie with the bite block and/or ETT holder. We connected the ETT to a digital force gauge and pulled perpendicular to the oral cavity, until the entire cuff was removed from the trachea. In each trial we considered the largest force recorded the extubation force. RESULTS: One of the conventional tape methods (with wider tape and longer tape strips) required the largest force to extubate. CONCLUSIONS: With tape strips of sufficient length and width, a conventional tape method was superior to the $\mathbf{2}$ tested commercial ETT holders in holding the ETT in place in the manikin. Key words: extubation force; adhesive tape; ETT holder; manikin. [Respir Care 2011;56(11):1825-1829. (C) 2011 Daedalus Enterprises]
\end{abstract}

\section{Introduction}

Tracheal intubation is a commonly performed intervention in anesthesia and intensive-care settings. The endotracheal tube (ETT) must be secured against accidental extubation or displacement, which can be life-threatening. The American Heart Association's 2005 Advanced Cardiac Life Support guidelines recommended either adhesive tape or an ETT holder to secure the ETT. ${ }^{1}$ In our institution the standard method in both the anesthesia setting and the intensive-care setting involves $1.3 \mathrm{~cm}$ wide adhesive

\footnotetext{
The authors are affiliated with the Department of Anesthesiology and Critical Care Medicine, University of Tsukuba, Tsukuba, Ibaraki Prefecture, Japan.

The authors have disclosed no conflicts of interest.

Correspondence: Takeru Shimizu MD PhD, Department of Anesthesiology and Critical Care Medicine, University of Tsukuba, Tennodai, Tsukuba, Ibaraki Prefecture, Japan 305-8575. E-mail: takerushimizu@ yahoo.co.jp.
}

DOI: $10.4187 /$ respcare.00954 tape (Durapore, 3M, St Paul, Minnesota), which is very simple and quick. However, to our knowledge no best method has been established.

Previous studies have compared conventional taping methods to various ETT holders. ${ }^{2-4}$ The Lillehei method (described elsewhere ${ }^{4,5}$ ) was regarded as a standard taping method in previous studies. However, to our knowledge the Lillehei method has not gained widespread popularity in clinical practice, and seems unsuitable in the emergency setting because it requires quite a few steps to prepare and place the pieces of tape. ${ }^{6}$ Instead of the Lillehei method, for simplicity, we attach adhesive tape on both sides of the face, along the upper and lower lips. To our knowledge there have been no studies of the extubation force required with different widths and/or lengths of adhesive tape. We measured the extubation force with conventional adhesive tape methods, with several tape widths and lengths, and with 2 commercially available ETT holders.

\section{Methods}

We used a simulation manikin (SimMan, Laerdal, Wappingers Falls, New York) and 9 different methods of 
Table 1. Endotracheal Tube Securement Methods

\begin{tabular}{lccc}
\hline \hline Endotracheal Tube Securement Method & $\begin{array}{c}\text { See } \\
\text { Figure(s) }\end{array}$ & $\begin{array}{c}\text { Tape } \\
\text { Width } \\
(\mathrm{cm})\end{array}$ & $\begin{array}{c}\text { Tape } \\
\text { Length } \\
(\mathrm{cm})\end{array}$ \\
\hline Durapore & $1 \mathrm{~A}$ & 1.3 & 10 \\
Durapore & $1 \mathrm{~B}$ & 1.3 & 15 \\
Durapore & $1 \mathrm{C}$ & 2.5 & 10 \\
Durapore & $1 \mathrm{D}$ & 2.5 & 15 \\
Wardel tape with bite block & $2-5$ & 5.0 & 10 \\
Multipore Dry with bite block & $2-5$ & 5.0 & 10 \\
LockTite with bite block & 5 & NA & NA \\
LockTite without bite block & 6 & NA & NA \\
Thomas endotracheal tube holder & 7 & NA & NA \\
& & & \\
NA = not applicable & & & \\
\hline
\end{tabular}

securing the ETT. The manikin was orally intubated with a standard intubation technique that included spraying an 86\% glycerol lubricant (Laerdal, Wappingers Falls, New York) into the manikin airway and inserting an 8.0-mm inner-diameter ETT (Rusch, United Kingdom) to the appropriate depth, confirmed via bronchoscopy. We inflated the ETT cuff to $20 \mathrm{~cm} \mathrm{H}_{2} \mathrm{O}$ with room air, and tested 9 ETT-securement methods (Table 1).

Per our standard clinical practice, when we tested $1.3 \mathrm{~cm}$ or $2.5 \mathrm{~cm}$ wide tape, the ETT was fixed at the right oral angle, without a bite block, and the tape was applied on both sides of the lips (Fig. 1). Benzoin was not used. We prepared the cloth tapes (Wardel, Taketora Holdings, Tokyo, Japan, and Multipore Dry, 3M, St Paul, Minnesota) as shown in Figure 2. When using the LockTite ETT holder (B\&B Medical Technologies, Carlsbad, California) with a device-specific bite block, the bite block was placed on the ETT through a slit along the long axis of the bite block after intubation, and cloth tape was applied (Figs. 3 and 4). Figures 5 and 6 show the application of the LockTite ETT holder, with and without the bite block. Figure 7 shows the application of the Thomas ETT holder (Laerdal, Wappingers Falls, New York).

We securely attached a digital push-pull force gauge (RX-100, Aikoh Engineering, Osaka, Japan) to the exposed end of the ETT, and manually extubated by grasping the ETT and gradually pulling it vertically, perpendicular to the oral cavity, with caution not to jerk the ETT, as described by Carlson et al. ${ }^{4}$ We defined extubation as full removal of the cuff past the vocal cords. We defined the extubation force as the maximum force during each extubation procedure. The force gauge reports measurements in Newtons. We ran 5 trials of each method. All of the procedures, including intubation, taping, and extubation, were performed by the same researcher (TS) to minimize procedural variation.
Statistical analysis (StatView, SAS Institute, Cary, North Carolina) was with analysis of variance and the Student $t$ test. A $P$ value of $<.05$ was considered significant.

\section{Results}

Table 2 shows the extubation force results. The conventional taping method with $2.5 \times 15 \mathrm{~cm}$ tape had the largest average extubation force $(131 \pm 12 \mathrm{~N})$. The LockTite ETT holder with bite block had the smallest average extubation force $(36 \pm 5 \mathrm{~N})$. Even the $1.3 \times 15 \mathrm{~cm}$ tape method was comparable to the $2.5 \times 15 \mathrm{~cm}$ tape method $(117 \pm 8 \mathrm{~N}$ vs $131 \pm 12 \mathrm{~N})$. The Thomas ETT holder had the third largest force $(106 \pm 4 \mathrm{~N})$, which was smaller than that of the $1.3 \times 15 \mathrm{~cm}$ tape method $(P=.03)$ and the $2.5 \times 15 \mathrm{~cm}$ tape method $(P=.005)$. The LockTite ETT holder had a greater extubation force without the bite block than with the bite block $(P=.01)$.

With the $5.0 \mathrm{~cm}$ wide cloth tape methods (see Figs. 5 and 6) the extubation force differed significantly between the tape brands ( $P<.001$ for Wardel vs Multipore Dry), similar to the conventional taping methods: Wardel $<1.3 \times 10 \mathrm{~cm}$ tape $<2.5 \times 10 \mathrm{~cm}$ tape $<$ Multipore Dry $<1.3 \times 15 \mathrm{~cm}$ tape $<2.5 \times 15 \mathrm{~cm}$ tape.

\section{Discussion}

The extubation force differed markedly between the 9 ETT-securement methods. Securing the ETT is a very important aspect of airway management in cardiopulmonary resuscitation, mechanical ventilation, and pulmonary toilet. Unplanned extubation or ETT displacement can cause serious adverse consequences, including death. There are no universally accepted ETT-securement methods, and only a few studies have reported some comparisons. ${ }^{7}$ The American Heart Association 2005 Advanced Cardiac Life Support guidelines recommended either tape or commercial devices to secure the ETT. ${ }^{1}$ Various ETT holders have been introduced commercially and studied. Carlson et $\mathrm{al}^{4}$ reported that the Thomas ETT holder had the largest extubation forces on cadavers (133-169 N), and Tube Tamer (ErgoMed, San Antonio, Texas), PM1110 (Precision Medical, Northampton, Pennsylvania), and Endogrip (Biomedix, Bloomington, Indiana) had extubation forces of 53, 44, $44 \mathrm{~N}$, respectively. The extubation force with the Lillehei method was $89 \mathrm{~N}$. The Durapore $1.3 \times 10 \mathrm{~cm}$ taping method is simple and quick, and had an extubation force of $49 \mathrm{~N}$, which was stronger than LockTite with bite block. The wider and longer the tape, the greater was the extubation force. The $1.3 \times 15 \mathrm{~cm}$ conventional taping method and the $2.5 \times 15 \mathrm{~cm}$ conventional taping method seemed to be stronger than the Lillehei method. We expected the $2.5 \mathrm{~cm}$ wide tapes to be approximately twice as strong as 


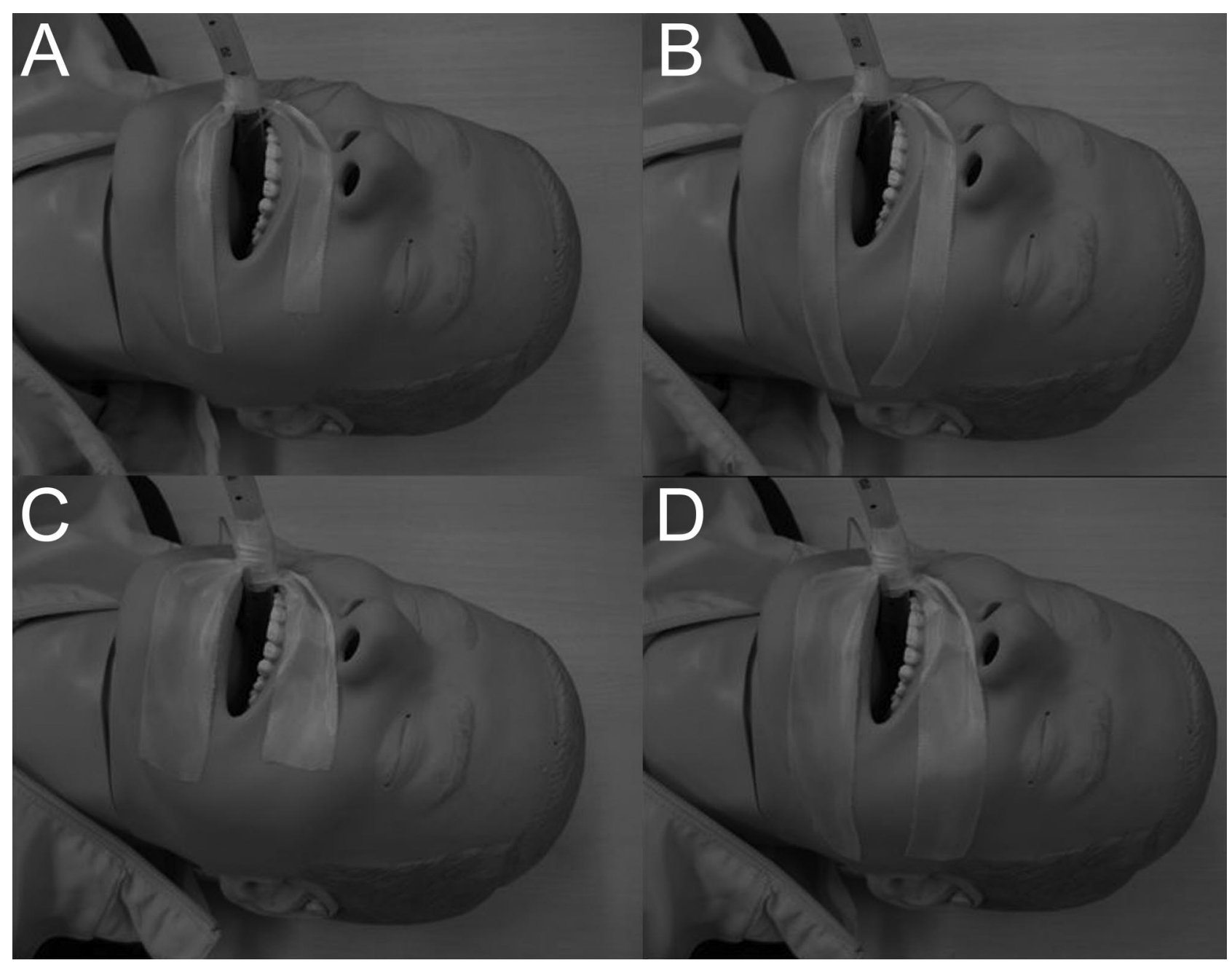

Fig. 1. Conventional endotracheal tube taping with Durapore tape of 4 widths and attachment lengths: $A: 1.3 \mathrm{~cm}$ wide, attached for $10 \mathrm{~cm}$. B: $1.3 \mathrm{~cm}$ wide, attached for $15 \mathrm{~cm}$. C: $2.5 \mathrm{~cm}$ wide, attached for $10 \mathrm{~cm}$. D: $2.5 \mathrm{~cm}$, attached for $15 \mathrm{~cm}$.

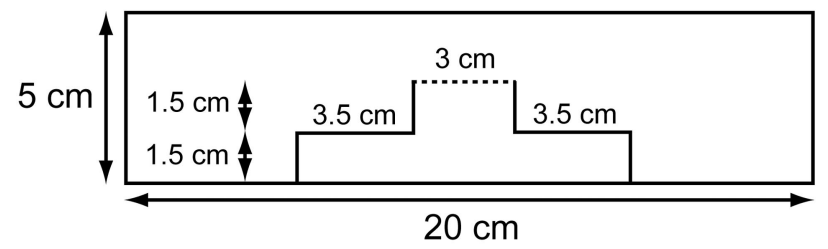

Fig. 2. Preparation of the cloth tapes (Multipore Dry and Wardel). Cuts were made along the solid lines, and a valley-fold was made along the dotted line.

the $1.3 \mathrm{~cm}$ tapes, depending upon the contact area, and this was almost true with the $10 \mathrm{~cm}$ tape lengths $(49 \mathrm{~N}$ vs $85 \mathrm{~N})$. However, the $2.5 \times 15 \mathrm{~cm}$ tape method had only slightly greater extubation force than the $1.3 \times 15 \mathrm{~cm}$ tape method (117 N vs $131 \mathrm{~N})$. It is likely that the contact area between the ETT and the tape would be a limiting factor.

The extubation forces we found with the ETT holders we tested were comparable to other ETT holders previously reported, and the LockTite ETT holder was basically

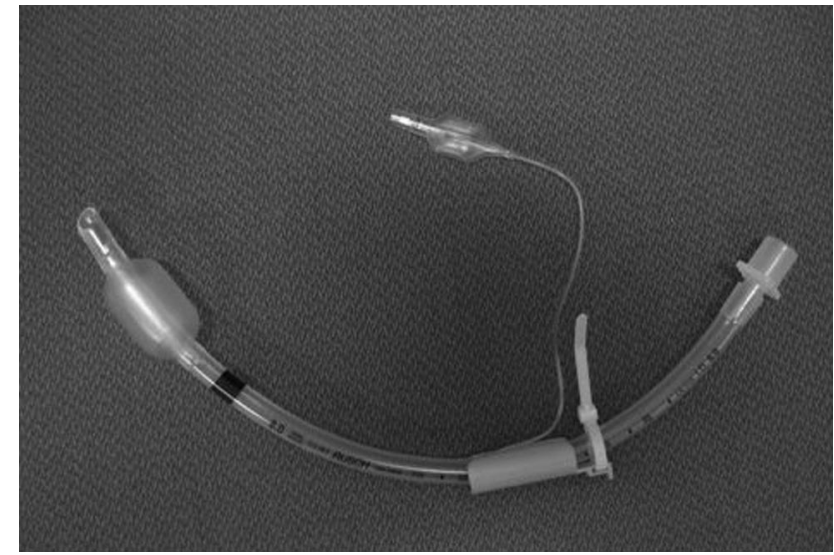

Fig. 3. Endotracheal tube with bite block.

weaker than the taping methods. The extubation force with the Thomas ETT holder was less than reported previously. ${ }^{4}$ The Thomas ETT holder tightens against the ETT with a 


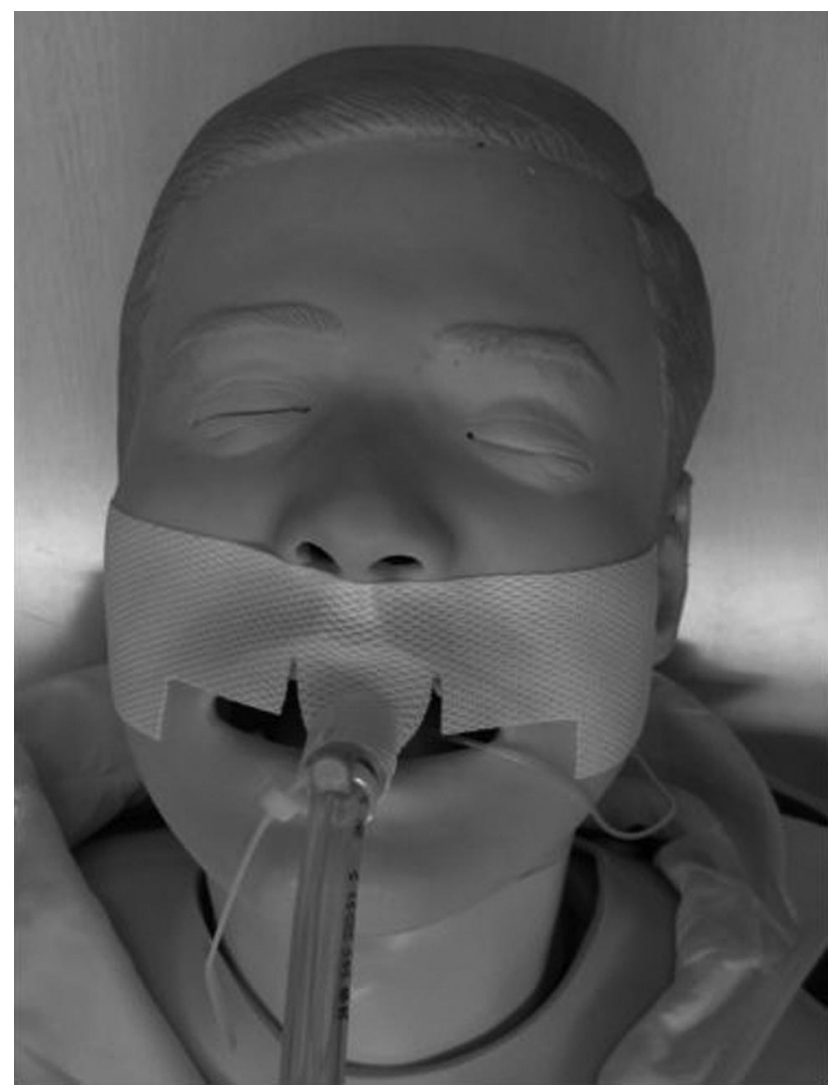

Fig. 4. Endotracheal tube with bite block, secured with cloth tape (Multipore Dry in this figure).

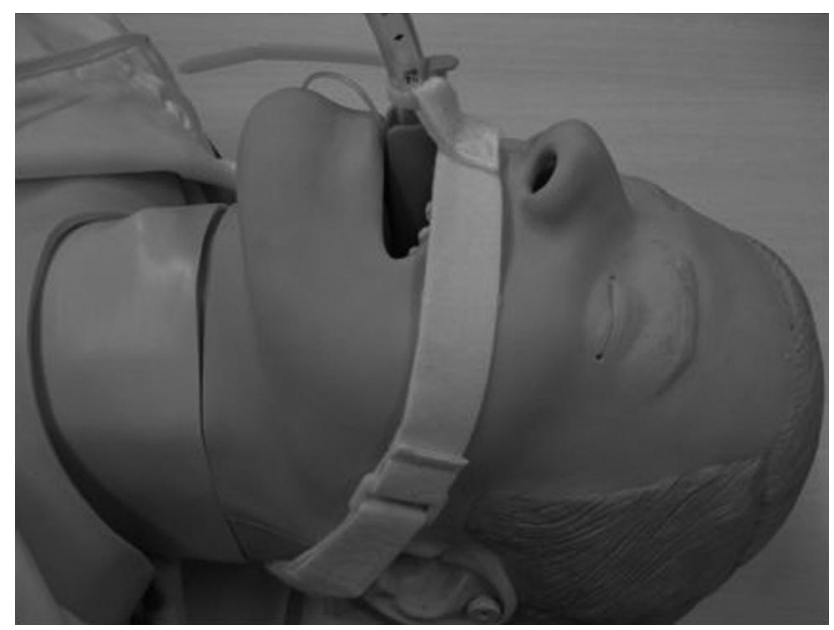

Fig. 5. Endotracheal tube with bite block, secured with LockTite endotracheal tube holder.

plastic screw, so the force may depend on the elasticity or friction resistance of the ETT material. Since there is no adhesive surface on the ETT holders, these devices may be useful if the patient's face is smudged with blood, vomitus, or dirt in emergency settings. Based on the pres-

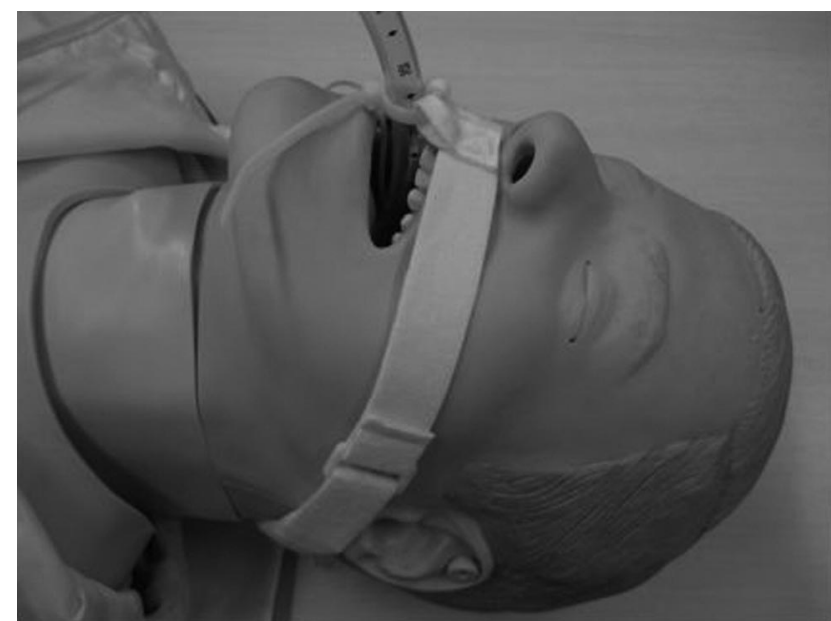

Fig. 6. Endotracheal tube without bite block, secured with LockTite endotracheal tube holder.

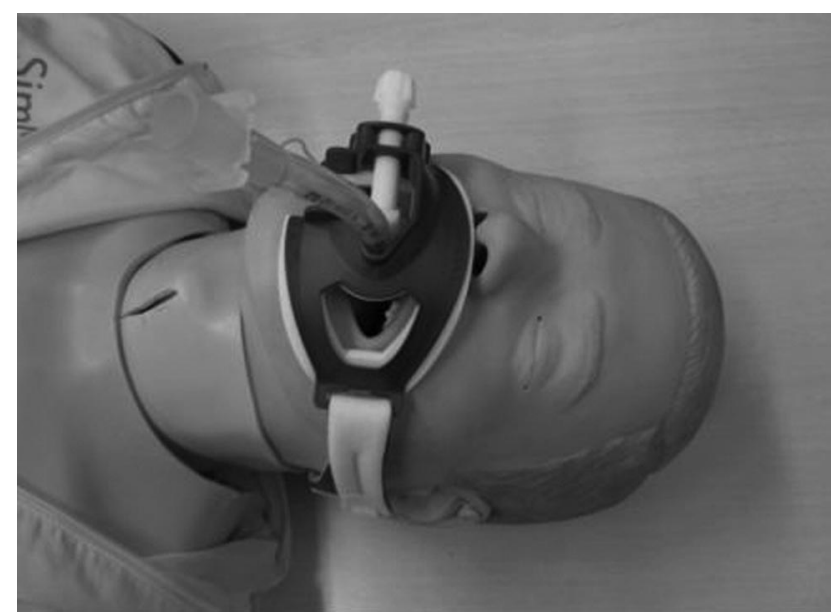

Fig. 7. Endotracheal tube secured with Thomas endotracheal tube holder.

ent results, we do not recommend the combination of Universal Bite Block and LockTite ETT holder.

\section{Limitations}

First, it is not clear that the force-measurement technique we used correlates well with conditions in clinical practice. ${ }^{4}$ Clinical conditions in the anesthesia setting might be similar to the conditions we modeled, because the ETTsecurement is required only for a short period, so there is no concern about loss of tape adhesion. The force in an intensive-care setting might be different, and the adhesive on the tape might be gradually denatured by sebum and loose adhesion. Thus, our manikin model does not fully simulate intensive-care conditions.

Second, force exerted on the ETT is usually in a relatively horizontal plane rather than a vertical and perpen- 
Table 2. Force Required to Extubate Tracheal Tube From the Manikin Airway*

\begin{tabular}{|c|c|c|c|c|c|c|c|c|c|}
\hline \multirow[b]{2}{*}{ Width $(\mathrm{cm})$} & \multicolumn{4}{|c|}{$\begin{array}{c}\text { Durapore Tape (conventional taping, } \\
\text { no bite block) }\end{array}$} & \multirow{2}{*}{$\begin{array}{c}\text { Wardel Tape } \\
\text { With } \\
\text { Bite Block }\end{array}$} & \multirow{2}{*}{$\begin{array}{c}\text { Multipore Tape } \\
\text { With } \\
\text { Bite Block }\end{array}$} & \multirow{2}{*}{$\begin{array}{c}\text { LockTite } \\
\text { Tube Holder } \\
\text { With } \\
\text { Bite Block }\end{array}$} & \multirow{2}{*}{$\begin{array}{c}\text { LockTite } \\
\text { Tube Holder } \\
\text { Without } \\
\text { Bite Block } \\
\text { NA }\end{array}$} & \multirow{2}{*}{$\begin{array}{c}\begin{array}{c}\text { Thomas Tube } \\
\text { Holder }\end{array} \\
\text { NA }\end{array}$} \\
\hline & 1.3 & 1.3 & 2.5 & 2.5 & & & & & \\
\hline Length (cm) & 10 & 15 & 10 & 15 & 10 & 10 & NA & NA & NA \\
\hline Bite block & None & None & None & None & Bite block & Bite block & Bite block & None & Device-specific \\
\hline Force $($ mean $\pm \mathrm{SD} N)$ & $49 \pm 5$ & $117 \pm 8$ & $85 \pm 5$ & $131 \pm 12$ & $42 \pm 3$ & $88 \pm 6$ & $36 \pm 5$ & $52 \pm 6$ & $106 \pm 4$ \\
\hline \multicolumn{10}{|c|}{$\begin{array}{l}\text { * All the differences were statistically significant except for the following } 4 \text { pairs: } 1.3 \mathrm{~cm} \times 10 \mathrm{~cm} \text { tape versus LockTite without bite block; } 1.3 \mathrm{~cm} \times 15 \mathrm{~cm} \text { tape versus } 2.5 \mathrm{~cm} \times 15 \mathrm{~cm} \text { tape; } \\
2.5 \mathrm{~cm} \times 10 \mathrm{~cm} \text { tape versus Multipore tape; and Wardel tape versus LockTite with bite block. } \\
\mathrm{NA}=\text { not applicable }\end{array}$} \\
\hline
\end{tabular}

dicular axis. We measured the extubation force in only one direction, but in practice the ETT can be pulled in various directions. We also studied only complete extubation, not partial extubation or displacement, since the surface of the manikin that we used does not expand like human skin. Furthermore, the manikin's lack of plasticity did not show gradual degrees of displacement: the ETT cuff was completely removed from the trachea when there was substantial displacement.

Third, the Lillehei method is often used as a representative taping method,2,4 but we did not test the Lillehei method because it involves a sophisticated procedure that seems to us impractical in the field or emergency settings, as Owen et al ${ }^{6}$ recently reported.

Fourth, our model lacked physiological airway mucus, so we used a lubricant. The extubation force without any fixation was $12.01 \pm 0.44 \mathrm{~N}$, which we considered negligible. Fifth, with a manikin it was impossible to assess skin breakdown or patient comfort. Ultimately, there may be a trade-off between ETT security and patient comfort. Sixth, we did not evaluate extubation force in patients with thick facial hair.

\section{Conclusions}

The conventional adhesive tape methods had greater extubation force than the 2 ETT holders. Although our manikin model did not completely simulate clinical conditions, clinicians should be aware that extubation force ranges considerably, depending on the width, length, and type of adhesive tape, or the kind of ETT-securement device. We recommend using sufficiently wide and long adhesive tape to secure the ETT. However, if the patient has thick facial hair such as mustache and/or beard, a commercially available ETT holder is recommended.

\section{REFERENCES}

1. American Heart Association. 2005 Guidelines for cardiopulmonary resuscitation and emergency cardiovascular care. Circulation 2005; 112(Suppl 24):IV-55.

2. Kaplow R, Bookbinder M. A comparison of four tracheal tube holders. Heart Lung 1994;23(1):59-66.

3. Tasota FJ, Hoffman LA, Zullo TG. Evaluation of two methods used to stabilize oral tracheal tubes. Heart Lung 1987;16(2):140-146.

4. Carlson J, Mayrose J, Krause R, Jehle D. Extubation force: tape versus endotracheal tube holders. Ann Emerg Med 2007;50(6): 686-691.

5. Roberts JR, Hedges JR. Clinical procedures in emergency medicine, 5th edition. Philadelphia: WB Saunders; 2010:71.

6. Owen R, Castle N, Hann H, Reeves D, Naidoo R, Naidoo S. Extubation force: a comparison of adhesive tape, non-adhesive tape and a commercial endotracheal tube holder. Resuscitation 2009;80(11): 1296-1300.

7. Levy H, Griego L. A comparative study of oral endotracheal tube securing methods. Chest 1993;104(5):1537-1540. 